\title{
IMPLEMENTASI WORK PASSION MELALUI MODAL PSIKOLOGI PADA KADER MASYARAKAT DESA CIAPUS, CIOMAS, BOGOR
}

\author{
Rita Markus Idulfilastri ${ }^{1}$, Francisca Iriani R.D ${ }^{2}$, dan Kintan Nurcahya Wailulu ${ }^{3}$
}

\author{
${ }^{1}$ Program Studi Magister Psikologi, Fakultas Psikologi, Univeristas Tarumanagara \\ Email:ritamarkus@fpsi.untar.ac.id \\ ${ }^{2}$ Program Studi Magister Psikologi, Fakultas Psikologi, Univeristas Tarumanagara \\ Email: fransicar@fpsi.untar.ac.id \\ ${ }^{3}$ Program Studi Magister Psikologi, Fakultas Psikologi, Univeristas Tarumanagara \\ Email: kintanwai93@gmail.com
}

\begin{abstract}
The results of the analysis of the problems of village cadres that have been fostered by the Association of Ambissi, seem still and need to be developed in terms of psychological aspects. They are enthusiastic about the activities that have been carried out but not yet wholeheartedly to develop their activities. Therefore, Community Village Cadre Assistance in Ciapus Village, Ciomas Subdistrict, Bogor Regency has the following objectives: (1) Village cadres know their abilities in terms of psychological capital. (2) Village cadres want to increase their enthusiasm for work so that they can excel in every activity. (3) Village cadres are able to develop activities based on the work plan they have made. The training method using the model of individual behavior change from Kurt Lewin is using unfrrezing, change and refreezing conditions. In accordance with the training method the unfreezing stage consists of group sessions; role session as village cadre; the change stage consists of individual target sessions ( 2 rounds); target group session; the refreezing stage consists of 3 month work target sessions and Psychology Capital sessions by filling out a questionnaire. Results and discussion of the types of participants in setting targets, (1) participants who know their abilities, but they are trying to achieve the target of reaching all balls; (2) participants who already know their abilities but are not satisfied; (3) participants who want to know their abilities; (4) participants who are looking for safety; (5) participants are aware of the risk, so that it becomes realistic. The results of the Psychology Capital questionnaire, in general village cadres have an optimistic attitude that is always a part of him and do not know to give up if there are difficulties always think about how to solve them. But that still needs to be improved on the aspects of hope, self efficacy and resilience. The conclusion of the training objectives is reached in terms of cognitive and affective and it is suggested to continue to examine the behavior.
\end{abstract}

Keywords: work passion; psychological capital; target; village cadre.

\begin{abstract}
ABSTRAK
Hasil analisis permasalahan para kader desa yang telah dibina oleh Perkumpulan Ambissi, kelihatan masih dan perlu dikembangkan dari sisi aspek-aspek psikologi. Mereka bersemangat dengan kegiatan-kegiatan yang telah dilakukan tapi belum sepenuh hati untuk mengembangkan kegiatannya. Oleh karena itu, Pendampingan Kader Desa Masyarakat Di Desa Ciapus, Kecamatan Ciomas, Kabupaten Bogor mempunyai tujuan (1) Para kader desa mengetahui kemampuan yang dimilikinya ditinjau dari modal psikologi. (2) Para kader desa mau meningkatkan gairah kerja sehingga berprestasi di setiap kegiatan. (3) Para kader desa mampu mengembangkan kegiatan berdasarkan rencana kerja yang dibuatnya. Metode pelatihan dengan menggunakan model perubahan perilaku individu dari Kurt Lewin yaitu menggunakan kondisi unfrrezing, change dan refreezing. Sesuai dengan metode pelatihan pada tahap unfreezing terdiri dari sesi berkelompok; sesi peran sebagai kader desa; tahap change terdiri dari sesi target individual (2 ronde); sesi target kelompok; tahap refreezing terdiri dari sesi target kerja 3 bulan dan sesi Modal Psikologi dengan mengisi kuesioner. Hasil dan pembahasan tipe peserta dalam menetapkan target yaitu (1) peserta yang tahu akan kemampuan dirinya, namun mereka berusaha agar target tercapainya tercapai yaitu bola masuk semua; (2) peserta yang sudah tahu kemampaun dirinya tapi merasa tidak puas; (3) peserta yang ingin tahu kemampuan dirinya; (4) peserta yang mencari aman; (5) peserta yang menyadari risiko, sehingga menjadi realistis. Hasil kuesioner isian kuesioner Modal Psikologi, pada umumnya para kader desa memiliki sikap optimis yang selalu menjadi bagian dirinya dan tidak kenal menyerah jika ada kesulitan selalu dipikirkan cara menyelesaikannya. Namun yang masih perlu ditingkakan pada aspek hope, self efficacy dan resilensi. Kesimpulan tujuan pelatihan tercapai dari sisi kognitif dan afektif dan disarankan dilanjutkan untuk menelaah dari perilaku.
\end{abstract}

Kata kunci: work passion, modal psikologi, target, kader desa 


\section{PENDAHULUAN}

Desa Ciapus terdiri 16 RW, 11.500 kepala keluarga dan sebanyak 3.500 kepala keluarga dengan status ekonomi miskin. Desa Ciapus merupakan desa dampingan (desdam) dari Perkumpulan Ambissi dengan menggunakan prinsip berkelanjutan, mengembangkan potensi lokal dan tidak menyebabkan ketergantungan maksudnya menciptakan kemandirian bagi desa. Pengembangan masyarakat desa ciapus melalui kaderisasi warga desa telah berhasil mengembangkan kegiatankegiatan yaitu pertanian kota, perbaikan lingkungan, pelayanan kesehatan (teska), taman baca, simpan pinjam, produk kuliner, kegiatan karitatif yaitu sedekah sapi, sembako murah, anak yatim, sunatan masal dan lain-lain. Pada setiap kegiatan telah dibentuk struktur organisasi yang terdiri dari koordinator kader, ketua kegiatan, wakil ketua kegiatan, sekretaris dan bendahara. Desa ciapus telah memiliki kader desa sebanyak 24 orang. Adapun kegiatan-kegiatan yang dikelola oleh kader desa yaitu Pelayanan Lingkungan, Taman Bacaan, Simpan Pinjam, Kuliner, Tanaman Obat.

Hasil analisis permasalahan para kader desa yang telah dibina oleh Perkumpulan Ambissi, kelihatan masih dan perlu dikembangkan dari sisi aspek-aspek psikologi. Mereka bersemangat dengan kegiatan-kegiatan yang telah dilakukan tapi belum sepenuh hati untuk mengembangkan kegiatannya. Para kader telah banyak terlibat dengan kegiatan teknis dan manajerial, misal mengatur pembagian tugas, mengalokasikan sumber daya dan waktu. Kondisi ini ditinjau dari aspek psikologi dikatakan belum memanfaatkan modal psikologi yang dimilikinya dan masih minim dalam hal memberikan semangat untuk dirinya sendiri. Oleh karena itu, Pendampingan Kader Desa Masyarakat Di Desa Ciapus, Kecamatan Ciomas, Kabupaten Bogor mempunyai tujuan sebagai berikut (1) Para kader desa mengetahui kemampuan yang dimilikinya ditinjau dari modal psikologi. (2) Para kader desa mau meningkatkan gairah kerja sehingga berprestasi di setiap kegiatan. (3)Para kader desa mampu mengembangkan kegiatan berdasarkan rencana kerja yang dibuatnya.

Hubungan modal psikologis dan gairah kerja merupakan hubungan sebab akibat, seorang yang mampu mengenali modal psikologis yang dimilikinya maka dengan sendiri akan berakibat pada meningkatnya gairah kerja. Terjalinnya hubungan gairah kerja dan modal psikologis dapat terjadi pada situasi atau kegiatan yang memerlukan tanggung jawab. Dengan demikian pada pengembangan diri para kader akan dilakukan berdasarkan 6 (enam) kegiatan yang telah ada. Secara konseptual hubungan antara gairah kerja dan modal psikologi dijelaskan di bawah ini.

Secara alami, setiap manusia memiliki kecenderungan untuk tumbuh dan berkembang, namun demikian hal ini tidak hanya bersifat natural melainkan juga kondisional yaitu membutuhkan dukungan lingkungan dan sosial untuk setiap orang dalam memenuhi kebutuhan dasar psikologis yaitu otonomi, kompeten dan keterhubungan dengan lingkungannya. Ketiga hal ini sangat penting bagi perkembangan pribadi para kader Desa yang bagian dari lingkungannya.

Dengan terpenuhinya kebutuhan dasar psikologis tersebut (autonomy, competence, relatedness) akan lebih mudah bagi para Kader desa untuk melakukan internalisasi sehingga muncul motivasi yang lebih bersifat intrinsik, merefleksikan minat dan nilai yang dimiliki, bukan karena ancaman atau tekanan dari luar (ekstrinsik). Namun demikian, perilaku yang didasari atas motivasi yang bersifat ekstrinsik dapat juga menjadi instrinsik melalui proses identifikasi dan penerimaan terhadap nilai dari perilaku ekstrinsik tersebut, yaitu ketika perilaku tersebut dapat diintegrasikan dengan nilai dan keyakinannya.

Modal psikologis lebih merupakan kondisi yang bisa berubah atau "state" dan bukan suatu yang menetap atau "traits". Artinya, modal psikologis sangat terbuka untuk bisa dikembangkan. Fluktuasi perubahan dipengaruhi oleh kondisi yang ada saat ini. Empat sumber modal psikologis cenderung bisa diperbaharui, saling melengkapi dan bersinergi. Dengan demikian, para kader desa atau tim kader desa yang memiliki modal psikologis yang tinggi dapat fleksibel dan beradaptasi dalam menghadapi tuntutan yang dinamis dalam pekerjaan. Disisi lain, modal psikologis secara 
simultan membantu para kader desa memiliki well-being dan tingkat kompetensi yang lebih tinggi (Luthans, Youssef-Morgan, Avolio, 2015).

\section{METODE PELAKSANAAN PKM}

Metode pelaksanaan PKM bersifat pendampingan, maksudnya Bagian 1 yaitu pada semester genap 2018-2019 diberikan pembekalan dalam bentuk Pelatihan dan pembuatan Rencana Kerja dan Bagian 2 yang akan dilaksanakan pada semester ganjil (2019-2020) merupakan monitoring kegiatan berdasarkan rencana kegiatan.

Metode pelaksanaan tahap 1, pertama-tama dilakukan penelaahan analisis kebutuhan kader masyarakat desa. Kegiatan dalam bentuk diskusi dan tanya jawab, rencana kegiatan pelatihan, waktu dan tempat pelatihan. Kemudian dilaksanan Pelatihan dengan menggunakan konsep psikologi Work Passion berdasarkan Modal Psikologi. Metode pelatihan dengan menggunakan model perubahan perilaku individu dari Kurt Lewin (Gambar 1).

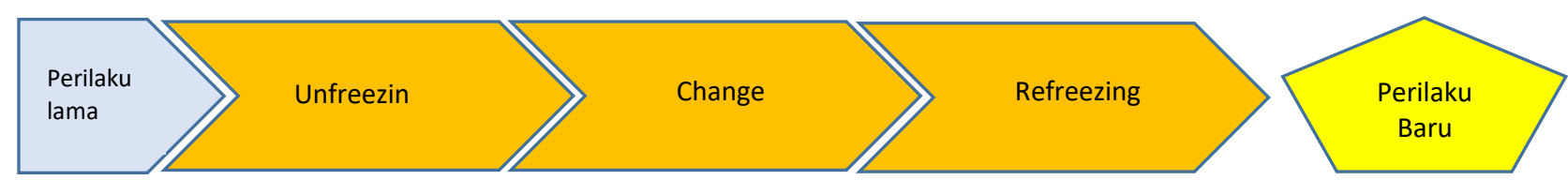

Gambar 1. Model Perubahan Perilaku menurut Kurt Lewin

Kondisi unfreezing merupakan proses menggerakkan dan menggugah peserta. Peserta yang meyakini atau menganggap sesuatu hal benar pada saat ini perlu diubah atau ditambah. Tujuan penggugahan agar peserta mau menerima hal-hal baru dengan tujuan menjadi lebih baik dari keadaan sebelumnya. Proses ini merupakan kegiatan yang paling penting karena mempengaruhi kegiatan-kegiatan di kondisi pada tingkat change dan tingkat refreezing. Ciri-ciri kegiatan kondisi unfeezing di pelatihan dikatakan berhasil bila peserta ingin lebih banyak tahu terhadap hal-hal baru. Kondisi change adalah kegiatan-kegiatan yang berhubungan dengan materi-materi baru yang perlu dipahami oleh peserta. Kondisi ini merupakan jawaban terhadap pertanyaan-pertanyaan peserta pada level unfreezing. Nilai-nilai baru merupakan bentuk dasar dari sikap dan perilaku baru yang diberikan dengan menggunakan teknik pembelajaran orang dewasa. Peserta merasakan secara langsung, menyimpulkan hasil pengalaman belajarnya dan diperkuat dengan teori, konsep dan fakta-fakta lapangan. Pada tahap refreezing adalah proses kegiatan yang memperkuat keyakinan peserta agar yang telah didapat selama pelatihan berguna dalam kehidupan atau khususnya di lingkungan kerja. Kegiatan yang dilakukan dengan membuat "Rencana Tindakan" sesuai dengan tujuan yang akan dicapai. Pada tahap refreezing ini, pendampingan dilakukan kegiatan membuat "Rencana Tindakan" pada 6 (enam) kegiatan. Kegiatan ini dipimipin oleh Ketua Kader kegiatan. Hasil rencana tindakan ini kemudian dipresentasikan dan diakhiri dengan kegiatan feedback session untuk meyakinkan dan memantapkan bahwa kegiatan-kegiatan tersebut dapat dilaksanakan.

Penguatan tahap refreezing dapat dilakukan melalui pengembangan modal psikologis. (1) efficacy, bisa dikembangkan dengan memberikan pengalaman dimulai dari yang sudah dikuasai, meniru (modelling), belajar dari pengalaman orang lain, persuasi sosial dan menumbuhkan semangat fisik maupun psikis; (2) hope, dikembangkan melalui melatih kemampuan menetapkan tujuan (goal setting), berpartisipasi dan merumuskan alternatif cara-cara untuk mencapai tujuan; (3) optimism, dikembangkan melalui penerimaan dan pembelajaran dari pengalaman masa lalu, menghargai saat ini dan mencari kesempatan untuk masa depan; (4) resilience, dikembangkan melalui strategi yang berfokus pada aset, strategi yang berfokus pada risiko dan strategi yang berfokus pada proses 
sebagai bahan pertimbangan dalam menginterpretasikan dan menggunakan aset dan risiko yang ada (Luthans, Youssef-Morgan, Avolio, 2015).

Pada dasarnya aspek-aspek yang dapat mengalami perubahan dari pelatihan adalah aspek kognisi, aspek afeksi dan aspek psikomotorik. Aspek kognisi berhubungan dengan pengetahuan yang didapat selama pelatihan, aspek afeksi berhubungan dengan pemahaman sehingga peserta memahami pentingnya suatu hal baru, sedangkan aspek psikomotorik berhubungan dengan adanya perubahan perilaku atau keterampilan yang diperoleh peserta. Oleh karena itu, kami membagi 2 (dua) bagian besar kegiatan Pendampingan Kader Masyarakat Desa Ciapus ini yaitu Bagian 1. Pendampingan perubahan pada aspek kognisi dan aspek afeksi dan Bagian 2. Pendampingan perubahan pada aspek perilaku. Pada pelaksanaan PKM semester ini, menguraikan kegiatankegiatan pada Bagian 1, sedangkan, Bagian 2 akan kami ajukan proposal pada semester berikutnya.

\section{HASIL DAN PEMBAHASAN}

Hasil kegiatan analisis kebutuhan pada tgl 18 Mei 2019 di Teska (Teras Kesehatan) Desa Ciapus, Bogor disepakati bahwa pelaksanaan pelatihan akan dilaksanakan pada tanggal 15 Juni 2019 bertempat di Yapipi, Ciapus, Bogor. Teknik pelatihan berdasarkan dari pengalaman para kader dan berdasarkan fakta dan data yang diperoleh.

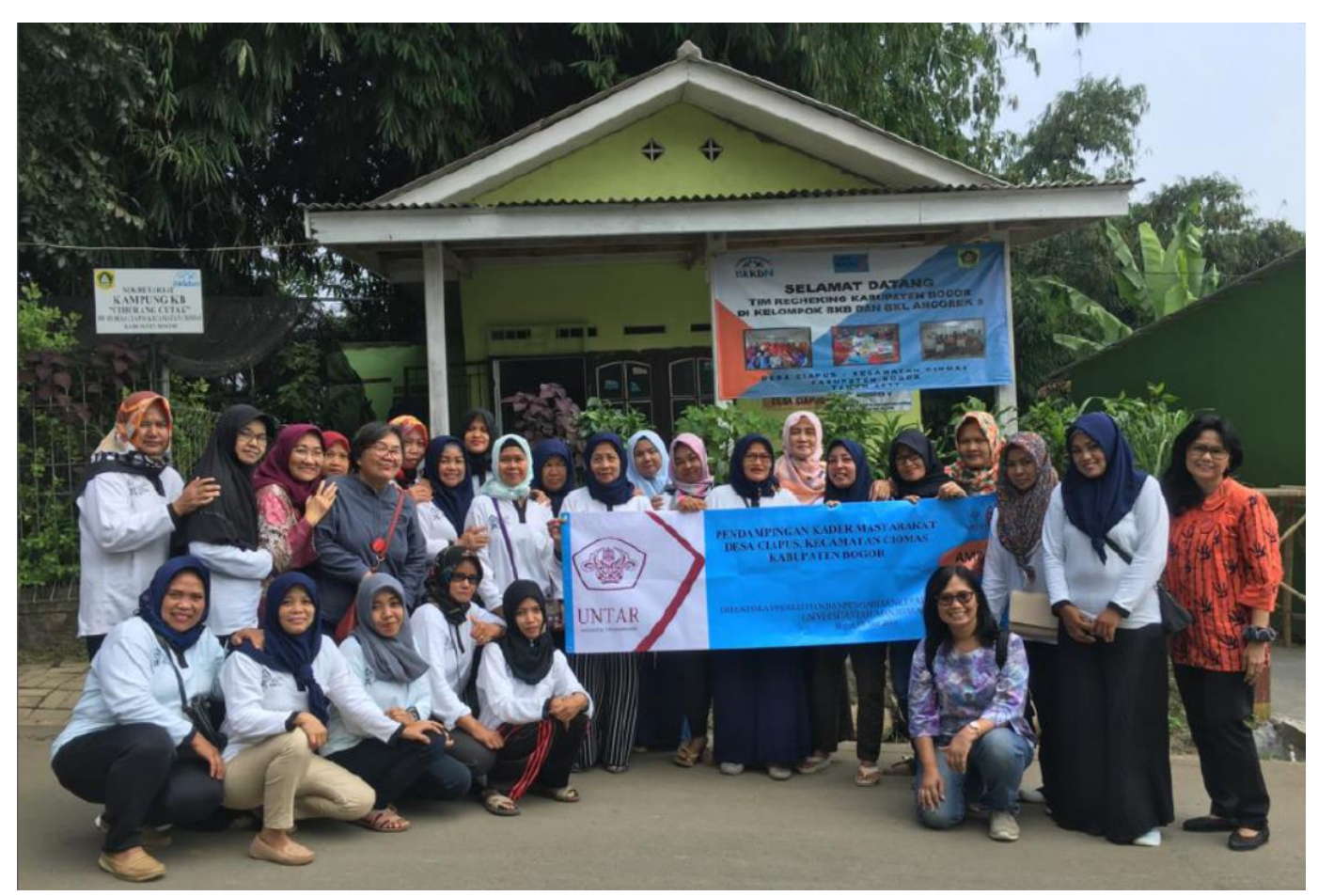

Gambar 2. Foto Bersama Para Kader Desa, Mitra Ambissi dan Tim PKM Untar di Teska, Ciapus

Kegiatan pelatihan dilaksanakan pada tgl 15 Juni 2019 (Gambar 2) yang dijabarkan dalam bentuk sesi-sesi pelatihan. Sesuai dengan metode pelatihan pada tahap unfreezing terdiri dari sesi berkelompok; sesi peran sebagai kader desa (Gambar 3); tahap change terdiri dari sesi target individual (2 ronde) (Gambar 4 dan Gambar 5); sesi target kelompok; tahap refreezing terdiri dari sesi target kerja 3 bulan (Gambar 6 dan Gambar 7). 


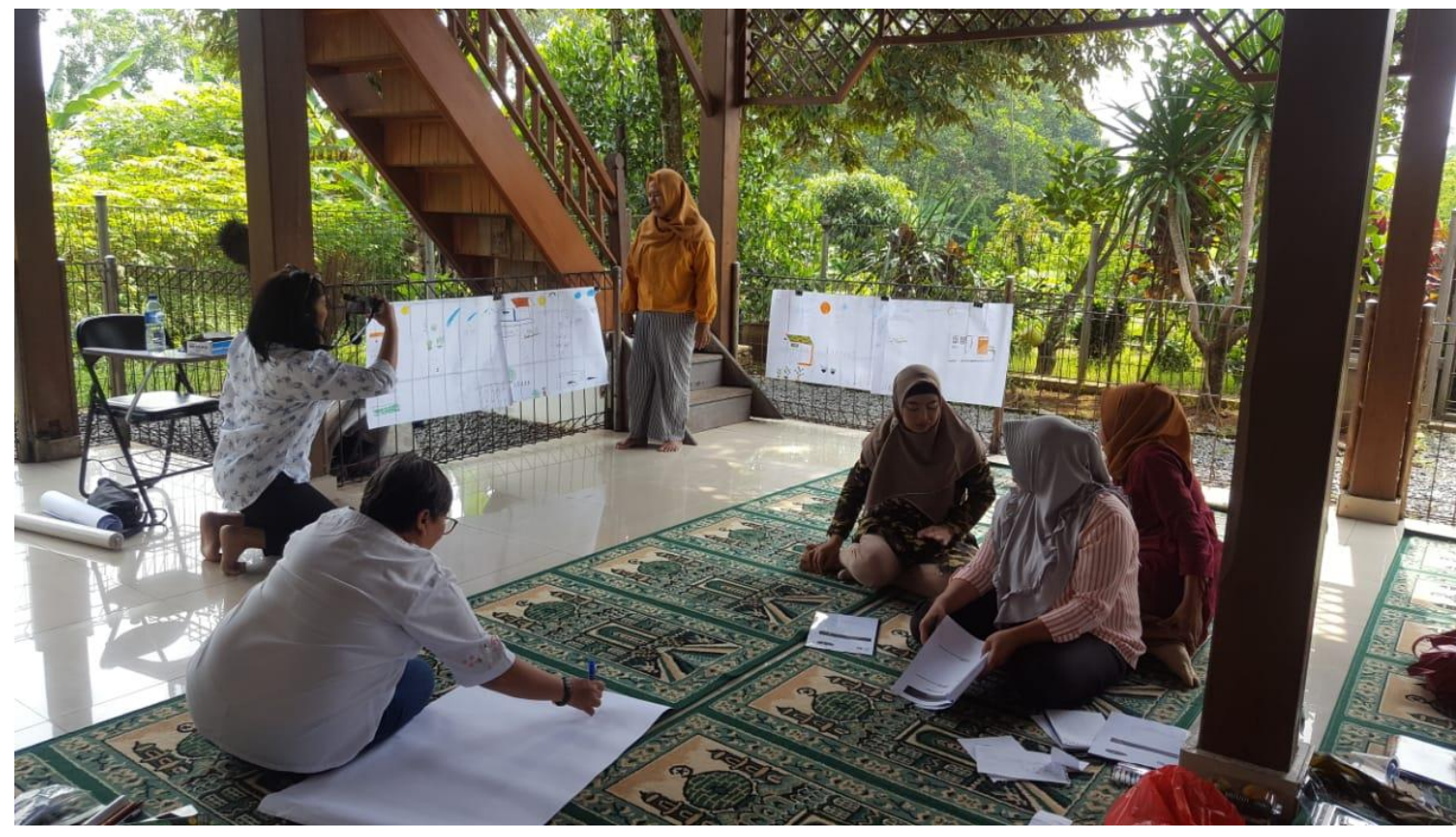

Gambar 3. Kegiatan sesi Peran sebagai Kader Desa

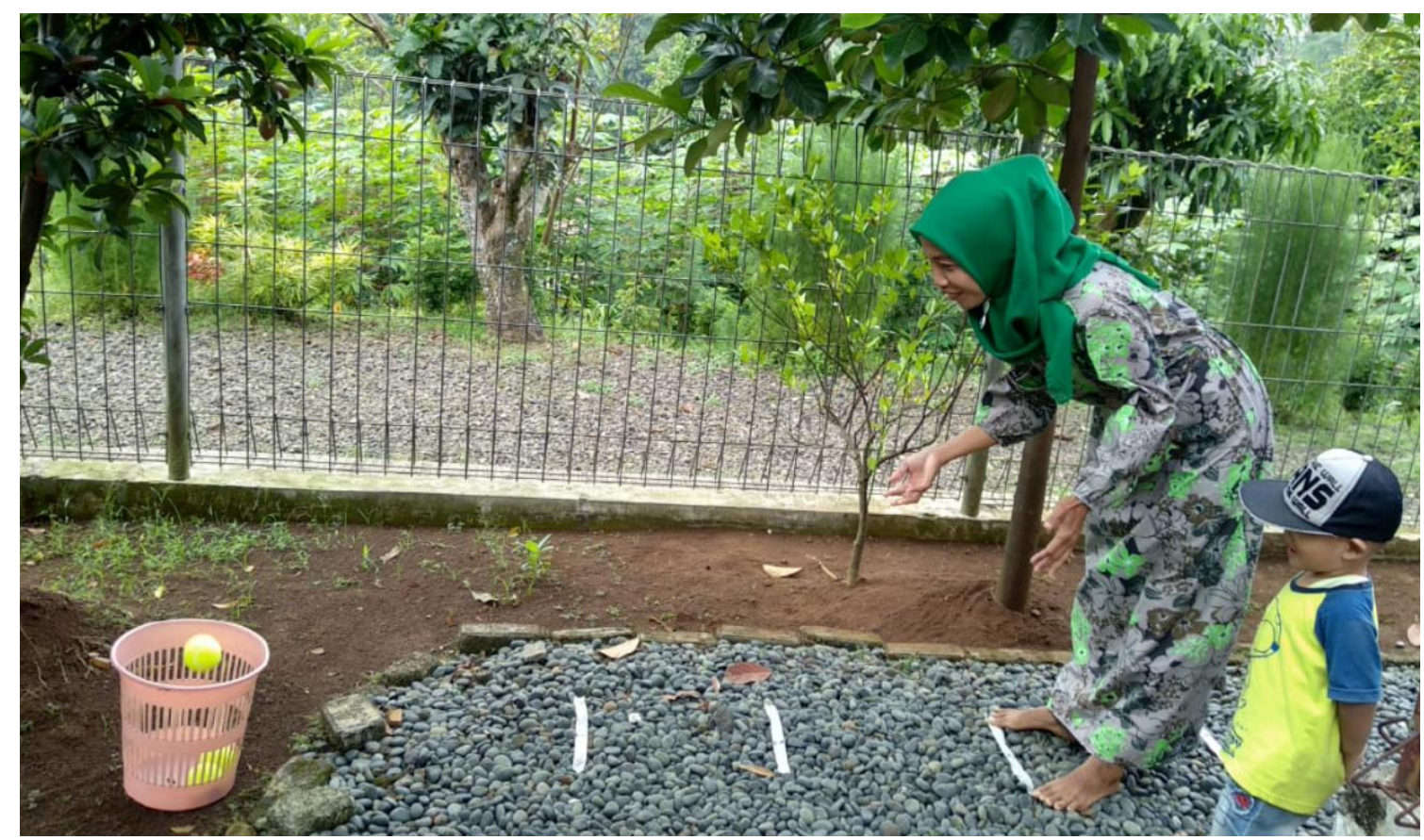

Gambar 4. Kegiatan sesi Target Individu 


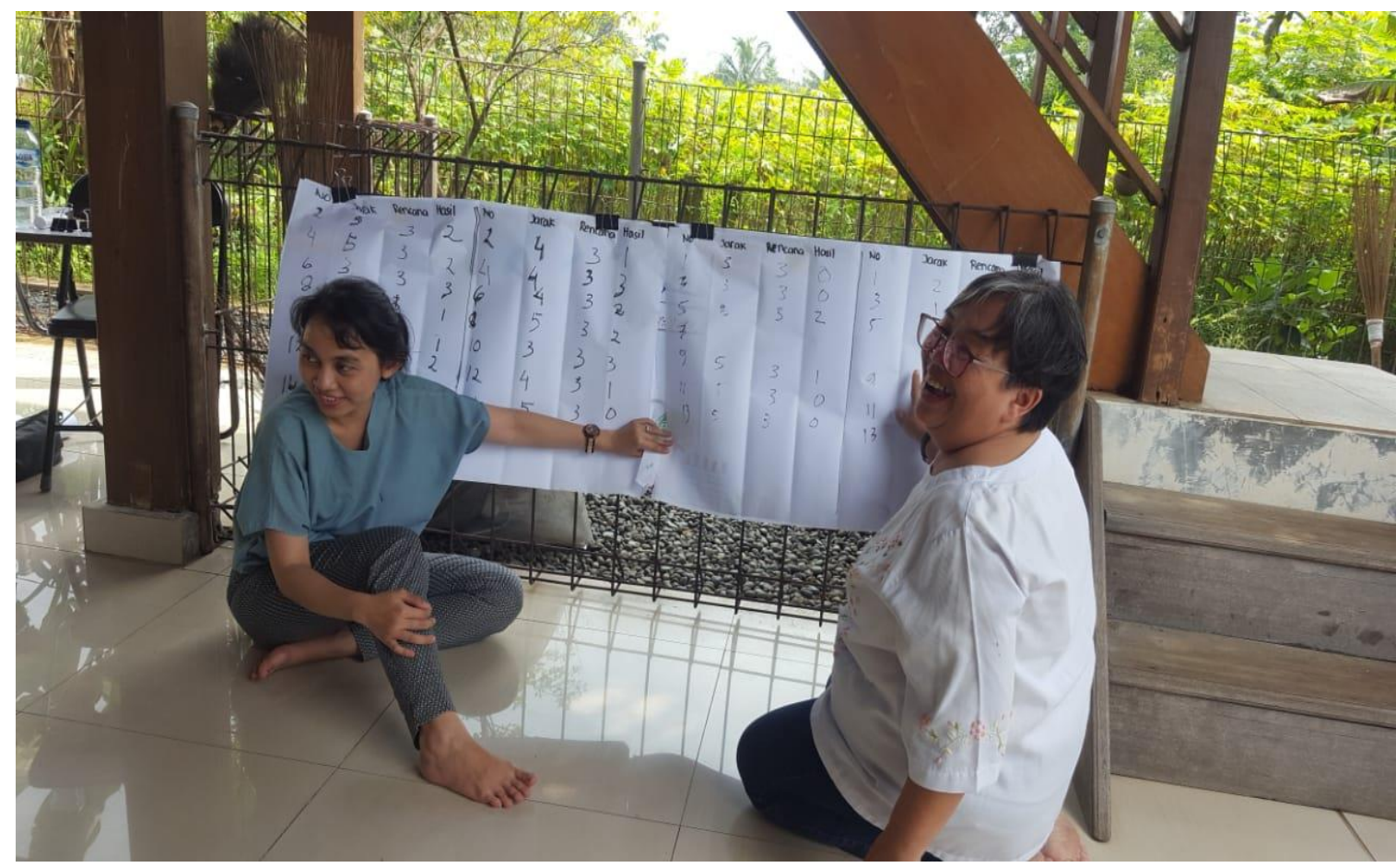

Gambar 5. Kegiatan sesi Target Individu - Pembahasan

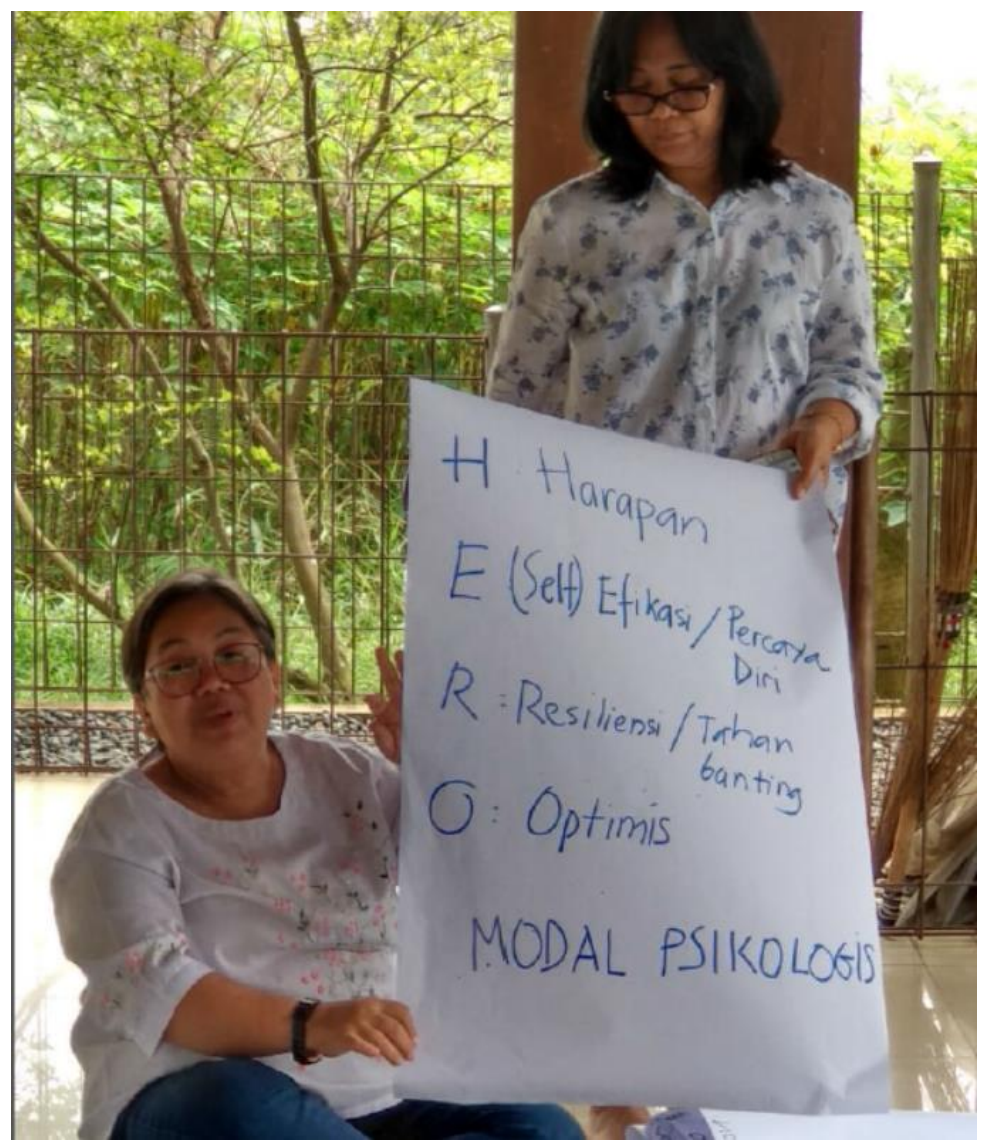

Gambar 6: Rencana Kerja 3 bulan - Pendahuluan 


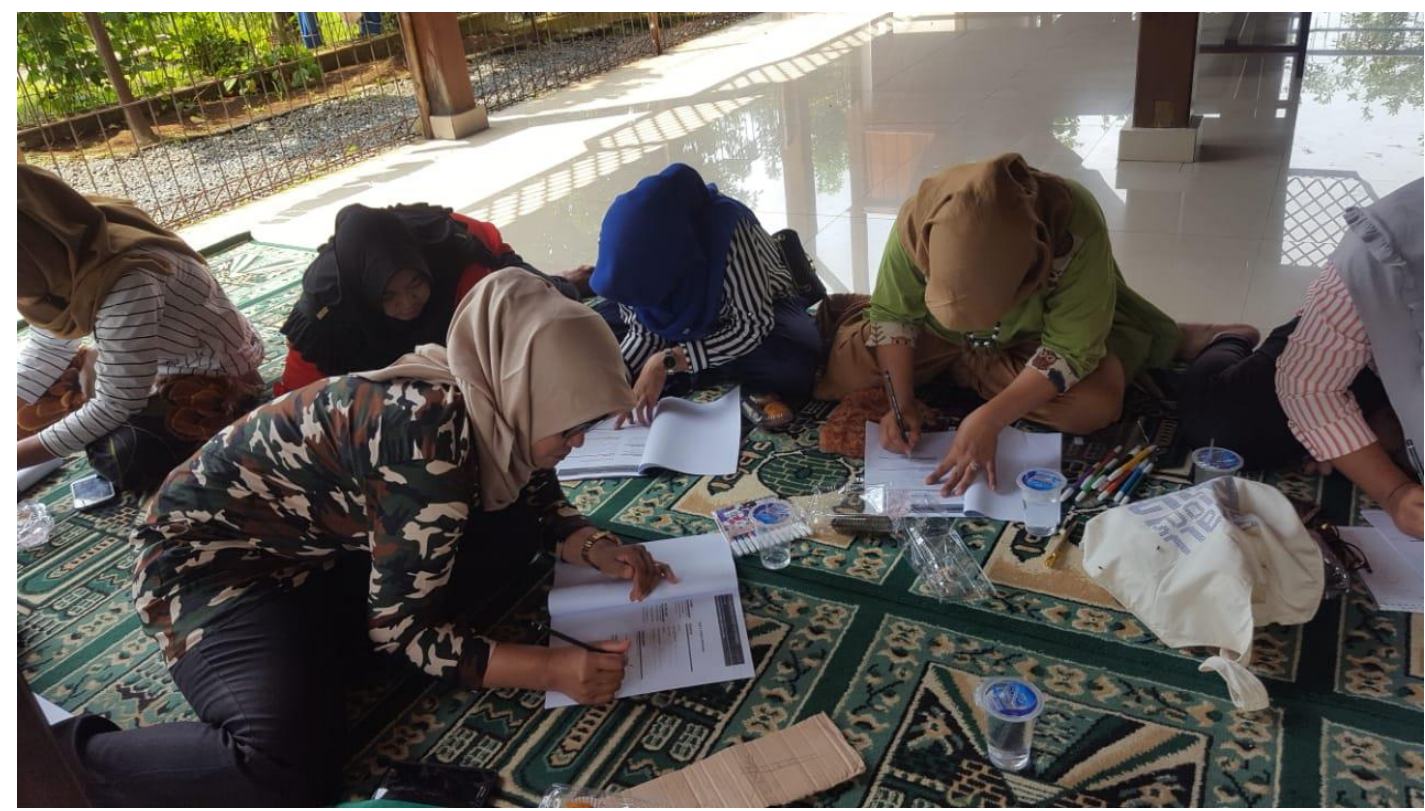

Gambar 7: Menyusun Rencana Kerja 3 bulan setiap kelompok kegiatan

Berdasarkan kegiatan sesi target individu yang dilakukan menggunakan simulasi dengan melempar bola pada jarak tertentu. Jarak bisa dipilih dari jarak 1 paling dekat dan jarak 10 paling jauh dari sasaran. Setaip peserta mendapatkan 3 bola dan dipersilakan memperkirakan kira-kira berapa bola yang masuk.

Tabel 1. Hasil lempar bola peserta

\begin{tabular}{cccc|ccc}
\hline Peserta & $\begin{array}{c}\text { Pilihan } \\
\text { Jarak }\end{array}$ & $\begin{array}{c}\text { Rencana } \\
\text { Bola Masuk } \\
\text { RONDE } 1\end{array}$ & $\begin{array}{c}\text { Hasil Bola } \\
\text { Masuk }\end{array}$ & $\begin{array}{c}\text { Pilihan } \\
\text { Jarak }\end{array}$ & $\begin{array}{c}\text { Rencana } \\
\text { Bola Masuk } \\
\text { RONDE 2 }\end{array}$ & $\begin{array}{c}\text { Hasil Bola } \\
\text { Masuk }\end{array}$ \\
\hline 1 & 3 & 3 & 0 & 2 & 3 & 3 \\
\hline 2 & 3 & 3 & 2 & 4 & 3 & 1 \\
\hline 3 & 3 & 3 & 0 & 1 & 3 & 3 \\
\hline 4 & 5 & 3 & 2 & 4 & 3 & 3 \\
\hline 5 & 3 & 3 & 2 & 4 & 3 & 1 \\
\hline 6 & 3 & 3 & 3 & 4 & 3 & 2 \\
\hline 7 & 5 & 3 & 0 & 4 & 3 & 2 \\
\hline 8 & 5 & 3 & 1 & 5 & 3 & 3 \\
\hline 9 & 5 & 3 & 1 & 4 & 3 & 2 \\
\hline 10 & 6 & 3 & 1 & 3 & 3 & 1 \\
\hline 11 & 5 & 3 & 0 & 3 & 3 & 0 \\
\hline 12 & 4 & 3 & 2 & 4 & 3 & 3 \\
\hline 13 & 5 & 3 & 2 & 5 & & 2 \\
\hline
\end{tabular}


Tabel 2. Hasil kuesioner Modal Psikologi $(n=13)$

\begin{tabular}{clc}
\hline Dimensi & \multicolumn{1}{c}{ Pernyataan } & Pilihan terbayak \\
\hline \multirow{2}{*}{ Hope } & $\begin{array}{l}\text { Jika saya menemukan kesulitan, saya memikirkannya } \\
\text { dengan banyak cara untuk menyelesaikannya. }\end{array}$ & Selalu \\
\cline { 2 - 3 } & $\begin{array}{l}\text { Saat ini, saya melihat diri saya sebagai orang yang } \\
\text { sukses }\end{array}$ & Tidak terlalu sering \\
\cline { 2 - 3 } & $\begin{array}{l}\text { Saya memikirkan banyak cara untuk mencapai target } \\
\text { kerja saya. }\end{array}$ & Sering \\
\cline { 2 - 3 } Self & $\begin{array}{l}\text { Saya merasa percaya diri mewakili teman-teman } \\
\text { sekelompok ketika ada rapat. }\end{array}$ & Sekali-kali saja \\
\cline { 2 - 3 } & $\begin{array}{l}\text { Saya merasa percaya diri jika berkontribusi di } \\
\text { kegiatan. }\end{array}$ & Kadang-kadang \\
\cline { 2 - 3 } & $\begin{array}{l}\text { Saya merasa percaya diri ketika menyajikan informasi } \\
\text { kepada rekan sekelompok kerja. }\end{array}$ & Sering \\
\cline { 2 - 3 } Resiliensi & $\begin{array}{l}\text { Saya bisa melewati masa-masa sulit karena saya } \\
\text { pernah mengalami kesulitan sebelumnya. }\end{array}$ & Sering \\
\cline { 2 - 3 } & $\begin{array}{l}\text { Saya bisa menjadi "diri saya sendiri", dapat berbicara } \\
\text { dimanapun jika memang diharuskan. }\end{array}$ & Kadang-kadang \\
\cline { 2 - 3 } & $\begin{array}{l}\text { Saya biasanya mengambil pekerjaan yang membuat } \\
\text { tertekan tapi dengan sikap tenang. }\end{array}$ & Kadang-kadang \\
\hline Pada saat ini, saya sedang berusaha meraih tujuan saya. & Selalu \\
\hline & $\begin{array}{l}\text { Saya selalu melihat sisi positif dari pekerjaan saya. } \\
\text { Optimis }\end{array}$ & Selalu \\
\cline { 2 - 3 } & $\begin{array}{l}\text { Saya optimis tentang masa depan saya yang berkaitan } \\
\text { dengan pekerjaan. }\end{array}$ & Selalu \\
\hline
\end{tabular}

Hasil lempar bola peserta pada Tabel 1 memperlihatkan peserta nomor 1, 4, 7, 9 merupakan peserta yang tahu akan kemampuan dirinya, namun mereka berusaha agar target tercapainya tercapai yaitu bola masuk semua. Pada peserta nomor 2, 5, 6 merupakan peserta yang sudah tahu kemampaun dirinya tapi merasa tidak puas. Pada peserta nomor 8, 12, 13 merupakan peserta yang ingin tahu kemampuan dirinya. Peserta no 3 merupakan peserta yang mencari aman, karena pilihan jarak 1 merupakan pilihan yang mudah dan sudah dapat dipastikan bola masuk. Peseta no 10 merupakan peserta yang menyadari risiko karena jarak tsb bukan kemampuannya walaupun ada bola masuk, tapi ia lebih realistis dan menurunkan jaraknya menjadi jauh lebih rendah.

Peserta diberikan kuesioner Modal Psikologi yang terdiri 12 butir dengan pilihan jawaban tidak pernah, sekali-kali saja, kadang-kadang, tidak terlalu sering, sering dan selalu. Modal psikologi terbagi 4 dimensi yaitu Hope, Self Efficacy, Resilensi, Optimis. Gambaran hasil Modal Psikologi dapat di lihat pada Tabel 2.

Hasil kuesioner peserta (Tabel 2), mempelihatkan para kader desa memiliki sikap optimis yang selalu menjadi bagian dirinya dan tidak kenal menyerah jika ada kesulitan selalu dipikirkan cara menyelesaikannya. Namun masih perlu peningkatan pada aspek Hope, Self Efficacy dan Resilensi.

\section{KESIMPULAN DAN SARAN}

Sesuai dengan tujuan Implemantasi Work Passion melalui Modal Pasikologi pada kader Desa Ciapus, Ciomas, Bogor dapat disimpulkan bahwa (1) Para kader desa mengetahui kemampuan yang dimilikinya ditinjau dari modal psikologi. Para kader desa mengetauhi bahwa mereka mempunyai kelebihan pada aspek optimis, dan masih perlu ditingkatkan pada aspek hope, self efficacy dan resilensi (2) Para kader desa mau meningkatkan gairah kerja sehingga berprestasi di setiap kegiatan. Para kader desa dapat menangkap esensi pada dirinya, apakah mereka sudah kenal 
betul akan kemapuan dirinya?; apakah mereka sudah memperhitungkan risiko atas keputusan yang diambilnya; apakah mereka tipe orang yang mencari aman saja; apakah mereka sudah tahu kemampuannya dan merasa belum puas jika targetnya belum tercapai. Atas pertanyaan-pertanyaan tersebut di dalam pembahasan para kader desa menjadi lebih menyadari atas dirinya (3) Para kader desa mampu mengembangkan kegiatan berdasarkan rencana kerja yang dibuatnya. Atas dasar arahan dari Buku Kerja setiap kelompok kegiatan membuat Rencana Kerja 3 bulan yang akan dating.

Pada dasarnya aspek-aspek yang dapat mengalami perubahan dari pelatihan adalah aspek kognisi, aspek afeksi dan aspek psikomotorik. Aspek kognisi berhubungan dengan pengetahuan yang didapat selama pelatihan, aspek afeksi berhubungan dengan pemahaman sehingga peserta memahami pentingnya suatu hal baru, sedangkan aspek psikomotorik berhubungan dengan adanya perubahan perilaku atau keterampilan yang diperoleh peserta. Oleh karena itu, kami membagi 2 (dua) bagian besar kegiatan Pendampingan Kader Masyarakat Desa Ciapus ini yaitu Bagian 1. Pendampingan perubahan pada aspek kognisi dan aspek afeksi telah kami laksanakan pada tanggal 8 Mei 2019 dan 15 Juni 2019. Untuk Bagian 2. Pendampingan perubahan pada aspek perilaku, kami sarankan dilanjutkan dan jika dimungkinkan pada pelaksanaan PKM semester ganjil 20192020.

\section{Ucapan Terima Kasih (Acknowledgement)}

Terima kasih kepada DPPM UNTAR yang telah memberikan fasilitas dan dukungan dana pada kegiatan PKM. Terima kasih juga kepada Mitra Ambissi terutama untuk Ira yang banyak membantu kami sehingga terselenggaranya kegiatan PKM. Terakhir kapada Dr. Ir. Anton Apriyantono dari YAPIPI yang telah menyediakan tempat pelatihan.

\section{REFERENSI}

Birkeland, I.K., Buch, R. (2015). The dualistic model of passion for work: descriminate and predictive validity with work engagement and workaholism. Motivation and Emotion, 39 (3), 392-408.

Cetin, F., Basim, H.N. (2012). Organizational psychological capital : a scale adaptation sudy. Todaie's Review of Public Administration, 6(1), 159-179.

Donahue, E.G, Forest, J.,Vallerand, R.J. (2012). Passion for work and emotional exhaustion : the mediating role of rumination and recovery. Applied Psychology: health and well-being, 4(3), 431-368.

Hagel, J., Brown, J.S., Ranjan, A., Byler, D. (2014). Passion at work: cultivating worker passion as a cornerstone of talent development. Deloitte University Press. Diambil dari : https://dupress.deloitte.com/dup-us-en/topics/talent/worker-passion-employeebehavior.html

Luthans, F., Yoessef-Morgan, C.M, Avolio, B.J. (2015). Psychological capital and beyond. USA: Oxford University Press.

Ryan, R.M., Deci, E.L. (2000). Self-determination theory and the facilitation of intrinsic motivation, social development and well-being. American Psychological Association, 55(1), 68-78.

Ryan, R.M., Deci, E.L. (2017). Self determination theory, basic psychological needs in motivation, development, and wellness. New York:The Guilford Press. 
Sunarsihanto, Pambudi. (2015). Talent Harus Mampu Hadapi VUCA World. Human Capital Journal. Diambil dari: http://humancapitaljournal.com/pambudi-sunarsihantotalent-harus-mampu-hadapi-vuca-world/

Vallerand, R.J., et al (2003). Les passion de $1^{\wedge}$ ame : on obessive and harmonius passion. Journal of Personality and Social Psychology, 85(4), 756-767.

Vallerand, R.J.(2012). The role of passion in sustainable psychological well-being. Psychology of Well Being, a Springer Open Journal, 2:1. Diambil dari : http://www.psywb.com/content/2/1/1.

Zigarmi, D., Nimon, K.,Houson, D.,Witt, D.,Diehl, J. (2011). A preliminary field test of an employee work passion model. Human Resources Development Quarterly, 12(2), 195 221.

Zhao, Y., St-Louis, A., Vallerand, R.J.(2015). On the validation of the passion scale in chinese. Psychology of Well Being, A Springer Open Jounal, 5(3). http://www.tribunnews.com/kemenko-pmk/2018/10/26/peran-revolusi-mental-sebagailokomotif-perubahan-indonesia?page=2. Jumat, 26 Oktober 2018 14:46 WIB 